\title{
Differentiation of Acetomonas and Pseudomonas
}

\author{
BY J. L. SHIMWELL \\ Research Department, British Vinegars Ltd., Frome, Somerset \\ J. G. CARR \\ Research Station, Long Ashton, Bristol \\ AND MURIEL E. RHODES \\ Department of Microbiology, University of Reading
}

(Received 4 April 1960)

SUMMARY

A comparative study of 50 strains of Acetomonas and 165 strains of Pseudomonas showed that the two genera could be easily and rapidly differentiated by the use of four criteria; these were: $(a)$ production of acid on ethanol $+\mathrm{CaCO}_{3}$ agar plates, $(b)$ oxidation of calcium lactate to carbonate, $(c)$ production and accumulation of dihydroxyacetone in glycerol media, $(d)$ growth at (initial) pH 4.5. Acetomonas was positive with $(a),(c)$ and $(d)$, but negative with $(b) ; P$ seudomonas was positive only with $(b)$. Liquefaction of gelatin and production of a greenish yellow fluorescent pigment, being variable with Pseudomonas and absent from Acetomonas, were useful only when positive.

\section{INTRODUCTION}

The belief in the universal polar flagellation of all motile acetic acid bacteria seems to have originated from the publication by Zeidler (1898) of a photomicrograph showing a single polar flagellum on several cells of Termobacterium aceti. Later, Vaughn $(1942,1943)$ published two papers with the stated purpose of drawing attention to the insufficiently recognized polar flagellation of all motile acetic acid bacteria, together with a photomicrograph of a cell with a single polar flagellum. These papers became widely known, and probably largely on this account Stanier (1947) was led to say 'In view of the extensive morphological and biochemical parallelism between acetic acid bacteria and organisms of the $\boldsymbol{P}$. fluorescens type, it seems indefensible any longer to maintain a family Acetobacteriaceae; its members should be incorporated in the family Pseudomonadaceae'. At the time this seemed supported by his statement that 'some fluorescent pseudomonads' could apparently produce some acid from ethanol when $\mathrm{CaCO}_{3}$ was present in the medium to neutralize free acid as soon as formed, and to prevent a decrease in $\mathrm{pH}$ value, for below $\mathrm{pH} \mathrm{5 \cdot 0}$ the bacteria rapidly died. It seems probable that the belief in the universal polar flagellation of the acetic acid bacteria became widely accepted for so long that it was thought unnecessary to stain the flagella of motile strains; they seem automatically to have been recorded as possessing 'a single polar flagellum'. Thus in the 6th edition of Bergey's Manual (1948) all motile Acetobacter strains were so described.

The work of Leifson (1954), confirmed by Shimwell $(1958,1959)$ and Asai \& Shoda (1958), however, has changed the picture. It is now known that motile 
acetate-oxidizing acetic acid bacteria have peritrichous flagella, and that it is only the motile ones which do not oxidize acetate (the 'suboxydans group' of Frateur, 1950) which have one or more (usually more) polar flagella. Although three years elapsed between Leifson's publication and the 7th edition of Bergey's Manual (1957) his findings were apparently not investigated, and the statement regarding the monotrichous polar flagellation of all motile strains of Acetobacter was repeated, on the grounds that Leifson's photomicrographs needed confirmation by unequivocal ones, or by electron micrographs, before his proposal to divide the acetic acid bacteria into Acetobacter (peritrichously flagellate, fully oxidizing) and Acetomonas (polarly flagellate, only partly oxidizing) could be accepted. This has since been done (Shimwell, 1958, 1959; Asai \& Shoda, 1958; Shimwell \& Carr, 1959), and there is no longer any doubt of the need to divide the heterogeneous acetic acid bacteria into their two component genera. Plate 1, fig. 1, shows the peritrichous flagella of a strain of Acetobacter rancens; Pl. 1, fig. 2, the polar ones of Acetomonas oxydans, the proposed type-species (Shimwell \& Carr, 1959).

Although Stanier (1947) was thus wrong in his insistence that all acetic acid bacteria should be recognized as pseudomonads and transferred from Acetobacteriaceae to Pseudomonadaceae, there still remained, however, the question whether the acetic acid production by some strains of Pseudomonas fuorescens constituted sufficient grounds for regarding them as acetic acid bacteria taxonomically indistinguishable from Acetomonas; or, conversely, whether Acetomonas strains should be included in Pseudomonas, there to swell the number of already overcrowded and often ill-defined species. The examination of this point is the main object of this paper.

To those only familiar with either Acetomonas or Pseudomonas a written list of the properties common to both genera, derived from the literature and specially selected to emphasize resemblances, might suggest that it is justifiable to put the two genera together. To those who have handled and studied members of both genera there seems less possibility of mistaking one for the other. Frateur (1950) enumerated some of the major differences between Pseudomonas and his suboxydans group (= Acetomonas) such as the inability of the acetic acid bacteria to liquefy gelatin, to show appreciable growth on peptone agar, to produce yellowish green fluorescent water-soluble pigments (admittedly not found in all Pseudomonas species), to grow on potato, to metabolize protein and so on. In addition to these negative properties of Acetomonas, however, we consider it important to emphasize their outstanding positive properties which are not possessed by $\boldsymbol{P}$. fluorescens and similar strains, and which sharply distinguish these two different types of bacteria.

\section{METHODS}

Strains used. These comprised the 50 Acetomonas strains previously studied by Shimwell \& Carr (1959), and the 165 Pseudomonas fuorescens and similar strains studied by Rhodes (1959; excluding Aeromonas strains).

Biochemical methods. These were mainly those described by Frateur (1950; some as modified by Shimwell \& Carr, 1959), and those of Rhodes (1959). It is convenient to give the methods used to obtain the results in Table 1.

(1) The production of acetic acid from ethanol was detected by the presence on agar plates of $1 \%(w / v)$ Difco yeast-extract $+2 \%(v / v)$ ethanol $+2 \%(w / v) \mathrm{CaCO}_{3}$, 
of clear zones of dissolved $\mathrm{CaCO}_{3}$ round the implanted $\left(c .1 \mathrm{~cm}^{2}\right)$ bacterial masses after incubation for 14 days at $26^{\circ}$, or sooner.

(2) Growth at $\mathrm{pH} 4 \cdot 5$. In the case of Pseudomonas strains this was studied in YE liquid medium adjusted to $\mathrm{pH} 4.5$ with $\mathrm{HCl}$ (Rhodes, 1959) and in similarly adjusted $1 \%(\mathrm{w} / \mathrm{v})$ Difco yeast extract $+2 \%(\mathrm{v} / \mathrm{v})$ ethanol, or similar alcoholic media in the case of Acetomonas strains, since the latter grow poorly (if at all) on YE liquid medium alone.

(3) Oxidation of calcium lactate through acetate to carbonate. This was studied on $1 \%(w / v)$ Difco yeast extract $+1 \%(w / v)$ calcium lactate agar plates, the production of carbonate being shown by the appearance of nodular crystals of $\mathrm{CaCO}_{3}$ under and/or around the implanted bacterial masses $\left(c .1 \mathrm{~cm} .{ }^{2}\right)$ as seen through the bottom of inverted plates at a magnification of $\times \mathbf{4 0}$.

Production and accumulation of dihydroxyacetone in media containing glycerol. Agar plates containing $1 \%(\mathrm{w} / \mathrm{v})$ Difco yeast extract $+2 \%(\mathrm{v} / \mathrm{v})$ glycerol were used. After various periods of incubation (1-14 days) at $26^{\circ}$, the plates were flooded, in the cold, with Fehling's solution, a quick (10 min.) production of an aureole of yellow to red copper oxide(s) round the implanted masses indicating the presence of dihydroxyacetone.

\section{RESULTS}

The results obtained with the primary differentiating criteria are recorded in Table 1. With the one exception in a total of 215 strains examined any one of the primary differentiating criteria served to eliminate either Acetomonas or Pseudomonas; any two of these criteria did so without exception (the one apparently anomalous strain will be referred to in the Discussion).

Table 1. The results of using the four primary differentiating tests with 50 Acetomonas and 165 Pseudomonas strains

\section{Test}

(a) Production of acetic acid on ethanol + $\mathrm{CaCO}_{3}$ agar

(b) Oxidation of lactate to carbonate

(c) Dihydroxyacetone from glycerol

(d) Growth at $\mathrm{pH} 4.5$

$\begin{array}{cc}\begin{array}{c}\text { Acetomonas } \\ \text { No. strains positive }\end{array} & \begin{array}{c}\text { Pseudomonas } \\ \text { No. strains positive }\end{array} \\ 50 \text { (in 2 days) } & 0 \text { (in 14 days) } \\ 0 & 165 \\ * 49 \text { (in } 18 \mathrm{hr} .) & 0 \text { (in } 14 \text { days) } \\ 50 & 0\end{array}$

* See Discussion.

There were secondary differentiating criteria which concerned characteristics which were never possessed by the Acetomonas strains, but which were usually (but not always) possessed by the Pseudomonas strains studied. These were the liquefaction of gelatin and the production of fluorescent yellow-green water-soluble pigment. These secondary differentiating characteristics, when positive, almost certainly rule out Acetomonas, but when negative are inconclusive. Other similar secondary criteria (e.g. peptonization of milk, etc.) are excluded as superfluous.

\section{DISCUSSION}

It is submitted that Acetomonas can readily be distinguished from Pseudomonas; indeed, it is virtually impossible to confuse them. We submit also that the differences shown in Table 1 are adequate and suitable for decisive, easy and rapid laboratory 
differentiation. Moreover, when these primary characters are considered in conjunction with the secondary characteristics, together with those listed by Frateur (1950) and by Rhodes (1959), it seems that there are relatively few resemblances between the genera Acetomonas and Pseudomonas apart from polar flagellation and an oxidative type of metabolism.

With regard to the one strain of Acetomonas which did not give dihydroxyacetone from glycerol, it was reported (Shimwell \& Carr, 1959) that this strain (A. suboxydans, NCIB 3734) also differed from the remaining 49 strains in not producing brown water-soluble pigment from any sugar used. As it was also non-motile, its differentiation from non-motile Acetobacter strains had to be based solely on its inability to oxidize acetic acid, lactate or acetate. It was suggested, however, (Shimwell, 1957) that in view of the facile mutability in Acetobacter, it was conceivable that even the ability to oxidize acetate might be capable of loss through mutation; and that if this were so, such a mutated Acetobacter strain might if non-motile be difficult to distinguish from a non-motile Acetomonas strain. We think that the anomalous strain in question may be an example of this possible situation. However, there is no question of the organism NCIB 3734 being a Pseudomonas strain, for it is a strong producer of acetic acid from ethanol, grows readily at $\mathrm{pH} 4 \cdot 5$, and does not oxidize acetic acid, acetate or lactate.

We wish to thank Mr W. Hodgkiss (Torry Research Station, Aberdeen) for his kindness in preparing the electron micrographs and Dr J. M. Shewan for his permission to publish them.

\section{REFERENCES}

Asar, T. \& Shoda, K. (1958). The taxonomy of Acetobacter and allied oxidative bacteria. J. gen. appl. Microbiol. 4, 289.

Bergey's Manual of Determinative Bacteriology (1948). 6th ed.; (1957) 7th ed. London: Baillière, Tindall and Cox.

Frateur, J. (1950). Essai sur la systématique des acetobacters. Cellule, 53, 287.

Leifson, E. (1954). The flagellation and taxonomy of species of Acetobacter. Leeurvenhoek ned. Tijdschr. 20, 102.

Rhodes, M. E. (1959). The characterization of Pseudomonas fluorescens. J. gen. Microbiol. 21, 221.

Shimweld, J. L. (1957). A pattern of evolution in the genus Acetobacter. J. Inst. Brew. 63, 45.

Shimweld, J. L. (1958). Flagellation and taxonomy of Acetobacter and Acetomonas. Leeurvenhoek ned. Tijdschr. $24,187$.

Shimweld, J. L. (1959). A re-assessment of the genus Acetobacter. Leeurvenhoek ned. Tijdschr. 25, 49.

Shrmwell, J. L. \& Carr, J. G. (1959). The genus Acetomonas. Leeuwenhoek ned. Tijdschr. 25, 353.

Stanier, R. Y. (1947). Acetic acid production from ethanol by fluorescent pseudomonads. J. Bact. 54, 191.

VaUghn, R. H. (1942). The acetic acid bacteria. Wallerstein Labs. Commun. 5, 5.

VAUGhN, R. H. (1943). Motility in the genus Acetobacter. J. Bact. 46, 394.

Zeidler, A. (1898). Photographisches Bild des Termobacterium aceti mit Geissel. Zbl. Bakt. 4, 669 .

\section{EXPLANATION OF PLATE}

Fig. 1. Acetobacter rancens strain. Electron micrograph showing peritrichous flagella. $\times 15,000$. Fig. 2. Acetomonas oxydans, cider strain. Electron micrograph showing multitrichous polar flagella. $\times 15,000$. 


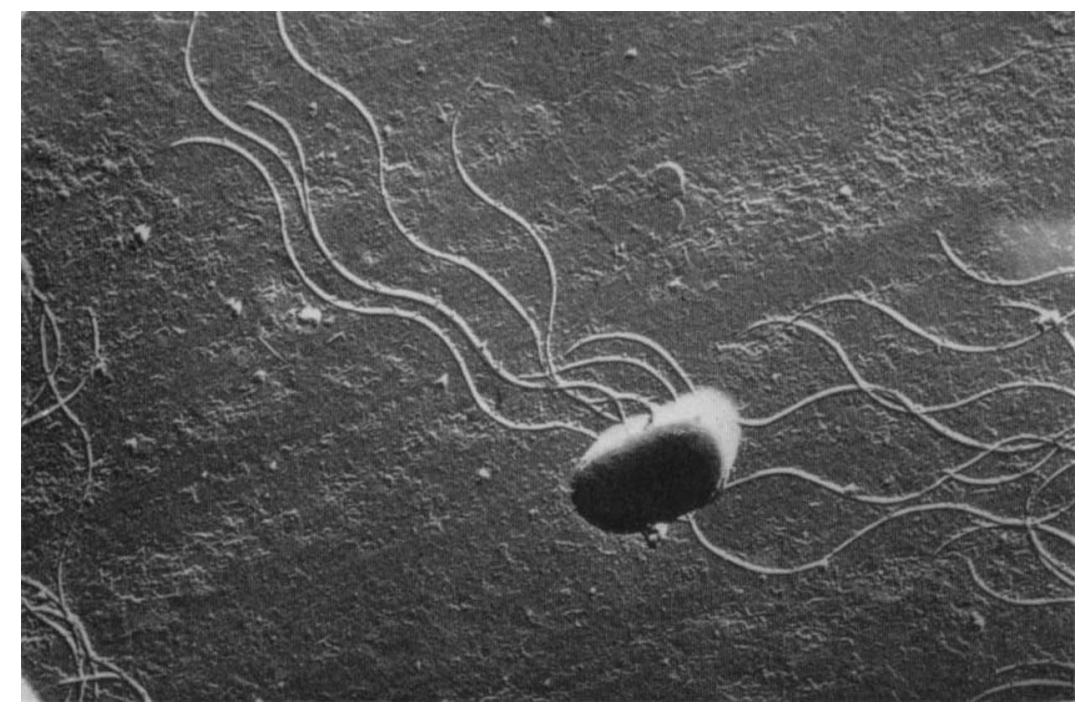

Fig. 1

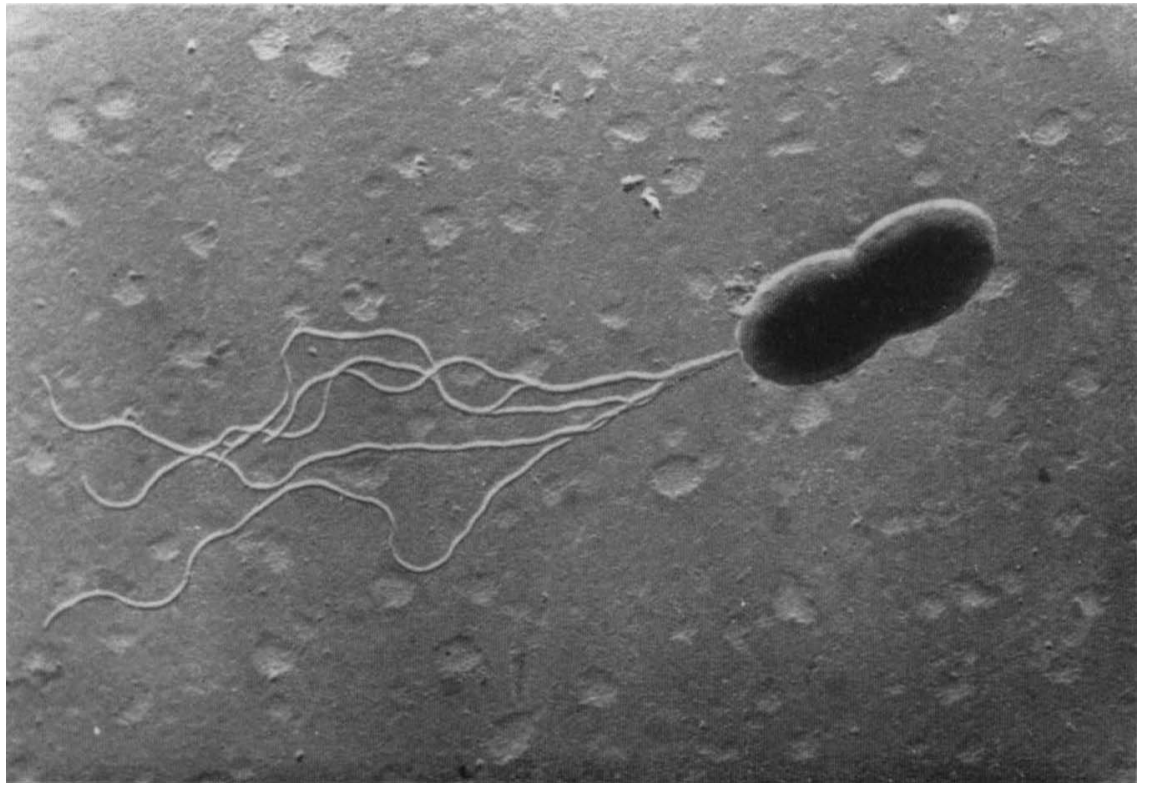

Fig. 2 